\title{
ORIGINAL ARTICLE Synergistic functions of E2F7 and E2F8 are critical to suppress stress-induced skin cancer
}

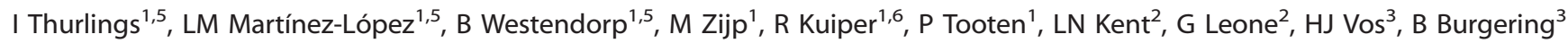 \\ and $A$ de Bruin ${ }^{1,4}$
}

E2F transcription factors are important regulators of the cell cycle, and unrestrained activation of E2F-dependent transcription is considered to be an important driver of tumor formation and progression. Although highly expressed in normal skin and skin cancer, the role of the atypical E2Fs, E2F7 and E2F8, in keratinocyte homeostasis, regeneration and tumorigenesis is unknown. Surprisingly, keratinocyte-specific deletion of E2F7 and E2F8 in mice did not interfere with skin development and wound healing. However, the rate for successful isolation and establishment of E2f7/8-deficient primary keratinocyte cultures was much higher than for wild-type keratinocytes. Moreover, E2f7/8-deficient primary keratinocytes proliferate more efficiently under stress conditions, such as low/high confluence or DNA damage. Application of in vivo stress using the DMBA/TPA skin carcinogenesis protocol revealed that combined inactivation of E2f7/8 enhanced tumorigenesis and accelerated malignant progression. Loss of atypical E2Fs resulted in increased expression of E2F target genes, including E2f1. Additional loss of E2f1 did not rescue, but worsened skin tumorigenesis. We show that loss of E2F7/8 triggers apoptosis via induction of E2F1 in response to stress, indicating that the tumorpromoting effect of E2F7/8 inactivation can be partially compensated via E2F1-dependent apoptosis. Importantly, E2F7/8 repressed a large set of E2F target genes that are highly expressed in human patients with skin cancer. Together, our studies demonstrate that atypical E2Fs act as tumor suppressors, most likely via transcriptional repression of cell cycle genes in response to stress.

Oncogene (2017) 36, 829-839; doi:10.1038/onc.2016.251; published online 25 July 2016

\section{INTRODUCTION}

Disruption of pathways controlling E2F activity is considered a critical event of tumorigenesis. ${ }^{1}$ Transcriptional activation of cell cycle genes by E2Fs is inhibited through direct interaction with the retinoblastoma protein (RB). ${ }^{2}$ Importantly, most human cancers show alterations in the upstream regulators of $\mathrm{RB}$, such as cyclins, or carry RB mutations resulting in disruption of RB/E2F interaction and consequently the upregulation of E2F-dependent transcription. ${ }^{3}$

Recent studies demonstrated that expression of E2F target genes is induced by transcriptional activator E2Fs, and counterbalanced by transcriptional repressors E2F7 and E2F8 during $\mathrm{S}$ - and G2-phase. ${ }^{1,4,5}$ In addition to their role to control this downswing of oscillating cell cycle genes, there is evidence that E2F7/8 are also involved in the transcriptional repression of cell cycle genes during DNA damage. ${ }^{6,7}$ E2F7 and E2F8 expression is induced in response to DNA damage, which is partially dependent on P53. ${ }^{6-8}$ The exact function of E2F7/8 during DNA damage is unclear, but transcriptional inhibition of cell cycle progression to enable optimal DNA repair is likely, as high E2F7/8 levels inhibit proliferation in vitro. ${ }^{4,9-14}$

There is evidence that E2F7/8 have a particularly important role in the maintenance of the squamous epithelium of the skin. In vitro experiments suggested that E2F7 downregulation drives squamous differentiation. ${ }^{15}$ Furthermore, E2F7 levels in squamous carcinoma cell lines affected proliferation and sensitivity to the chemotherapeutic drug doxorubicin. ${ }^{16}$ In vivo studies on the function of E2F7 and E2F8 in skin are currently lacking. We show here that E2F7/8 are dispensable for normal skin function and wound healing, but deletion leads to increased numbers of skin tumors and enhanced malignant progression in a two-stage skin carcinogenesis model. E2F7/8-deficient keratinocytes displayed increased expression of E2F1 and enhanced apoptosis during tumor initiation. Loss of E2F1 reduced apoptosis and accelerated tumorigenesis in E2F7/8-deficient tumors. These findings suggest that E2F1-induced apoptosis might partially compensate for the loss of the tumor suppressor functions of E2F7/8.

\section{RESULTS}

Atypical E2F function is not required for skin development, maintenance and regeneration

Our previous studies demonstrated that synergistic functions of atypical E2Fs are essential for placental development and embryonic survival in mice. ${ }^{17,18}$ To investigate the role in adult tissues, we conditionally ablated E2F7 and E2F8 in the skin. ${ }^{9,14}$ We crossed $E 2 f 7^{\text {LoxP/LoxP }}{ }_{;} E 2 f 8^{\text {LoxP/LoxP }}$ mice (from here on referred to as control) with transgenic $\mathrm{K} 14-\mathrm{Cre}$ mice. We confirmed keratinocytespecific Cre activity by interbreeding the $K 14-C r e ; E 2 f 7^{\Delta / \Delta} ; E 2 f 8^{\Delta / \Delta}$ mice (from here on referred to as $E 2 f 7^{\Delta / \Delta} E 2 f 8^{\Delta / \Delta}$ mice) with

\footnotetext{
${ }^{1}$ Department of Pathobiology, Faculty of Veterinary Medicine, Utrecht University, Utrecht, The Netherlands; ${ }^{2}$ Department of Molecular Virology, Immunology, Medical Genetics, Comprehensive Cancer Center, The Ohio State University, Columbus, OH, USA; ${ }^{3}$ Molecular Cancer Research, University Medical Center Utrecht, Utrecht, The Netherlands and

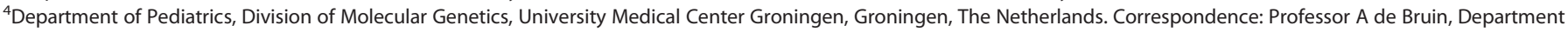
of Pathobiology, Faculty of Veterinary Medicine, Utrecht University, Yalelaan 1, Utrecht 3584CL, The Netherlands.

E-mail: a.debruin@uu.nl

${ }^{5}$ These authors contributed equally to this work.

${ }^{6}$ Current address: Karolinska Institute, Department of Laboratory Medicine, Karolinska University Hospital Huddinge, 17177 Stockholm, Sweden.

Received 13 November 2015; revised 21 April 2016; accepted 1 June 2016; published online 25 July 2016
} 
Cre-reporter mice $\left(R 26 R\right.$-Lac $\left.Z^{\text {LoxP/LoxP }}\right)$. LacZ expression was detected in keratinocytes of adult $K 14-C r e ; E 27^{\Delta / \Delta} ; E 2 f 8^{\Delta / \Delta} ; R 26 R^{\Delta / \Delta}$ mice (Figure 1a).

Mice with keratinocyte-specific combined deletion of E2f7 and $E 2 f 8$, as well as mice with conventional single deletion of E2f7 or E2f8 were monitored until old age. Survival between these ageing cohorts did not differ and histopathological analysis of the skin revealed no significant microscopic lesions compared with age-matched control littermates (Figure $1 \mathrm{~b}$, data not shown). Wound-healing assays revealed that combined loss of E2f7 and E2f8 did not perturb skin regeneration in vivo (Figure 1c). Together, these data suggest that atypical E2Fs are not required for skin development, maintenance and regeneration in mice.

These findings are surprising, because previous in vitro studies indicated that E2F7 can regulate proliferation and survival in human primary keratinocytes. ${ }^{19}$ We therefore isolated primary keratinocytes from our mice to determine whether inactivation of atypical E2Fs had any impact on proliferation or apoptosis under in vitro conditions. We confirmed absence of targeted mRNA and proteins in extracts from primary keratinocytes (Supplementary Figure 1). Interestingly, we observed that the success rate for establishment of primary keratinocyte cultures was higher for $E 2 f 7^{\Delta / \Delta} E 2 f 8^{\Delta / \Delta}$ keratinocytes than for control keratinocytes (Figure 2a). These observations suggest that $E 2 f 7^{\Delta / \Delta} E 2 f 8^{\Delta / \Delta}$ keratinocytes might have a growth advantage under severe stress conditions. Next, we cultured keratinocytes under low- and highconfluence conditions and found that $E 2 f 7^{\Delta / \Delta} E 2 f 8^{\Delta / \Delta}$ keratinocytes reached higher cell counts than control keratinocytes (Figure $2 b$ ).

Our previous studies demonstrated that E2F1 is a key transcriptional target of the atypical E2Fs and inactivation of E2F1 rescued multiple phenotypes induced by inactivation of E2F7/8. ${ }^{18,20}$ To explore whether E2F1 contributes to enhanced growth performance of $E 2 f 7^{\Delta / \Delta} E 2 f 8^{\Delta / \Delta}$ keratinocytes, we generated $K 14-C r e-E 2 f 7^{\Delta / \Delta} E 2 f 8^{\Delta / \Delta} ; E 2 f 1^{-/-}$mice and isolated primary keratinocytes with triple deletions. The isolation and successful establishment of primary $E 2 f 7^{\Delta / \Delta} E 2 f 8^{\Delta / \Delta} E 2 f 1^{-1}$ cultures occurred at similar efficiency as for $E 2 f 7^{\Delta / \Delta} E 2 f 8^{\Delta / \Delta}$ cultures (Figure 2a). Surprisingly, $E 2 f 7^{\Delta / \Delta} E 2 f 8^{\Delta / \Delta} E 2 f 1^{-1-}$ keratinocytes reached higher cell counts than $E 2 f 7^{\Delta / \Delta} E 2 f 8^{\Delta / \Delta}$ under low confluence and similar cell counts under high-confluence conditions (Figure 2b). These findings suggest that increased expression of E2F1 in E2f7 ${ }^{\Delta / \Delta} E 2 f 8^{\Delta / \Delta}$ keratinocytes does not contribute to increased proliferation rate, but instead has an inhibitory effect on cell growth performance of $E 2 f 7^{\Delta / \Delta} E 2 f 8^{\Delta / \Delta}$ keratinocytes. We failed to isolate keratinocytes from $E 2 \mathrm{f1}^{-/}$mice, which is in line with previous studies describing that reduced levels of E2F1 can lead to growth arrest in keratinocytes. ${ }^{21}$ Interestingly, this inability to isolate and culture $E 2 \mathrm{f1}^{-1-}$ keratinocytes can be rescued by inactivation of atypical E2Fs, providing further support that loss of E2F7/8 makes keratinocytes more resistant against stress signals that inhibit proliferation.

E2F7/8 inhibit DNA replication during DNA damage in primary keratinocytes

We next exposed our primary keratinocytes to DNA damage agents, as previous studies suggest that E2F7/8 have a role in the DNA damage response. ${ }^{6-8,22}$ However, these previous studies were performed in transformed human cancer cell lines, in which the physiological DNA damage response might already be altered. Furthermore, mechanisms how E2F7/8 participate in the DNA damage response are still unclear. We treated keratinocytes with etoposide, a topoisomerase II inhibitor that causes singleand double-strand DNA breaks, to induce DNA damage. ${ }^{23}$ DNA damage was quantified at single-cell level by performing phosphorylated $\mathrm{\gamma H} 2 \mathrm{Ax}$ immunofluorescence staining and analyzing the fluorescence intensity per keratinocyte nucleus. Eight hours of etoposide treatment resulted in significantly increased

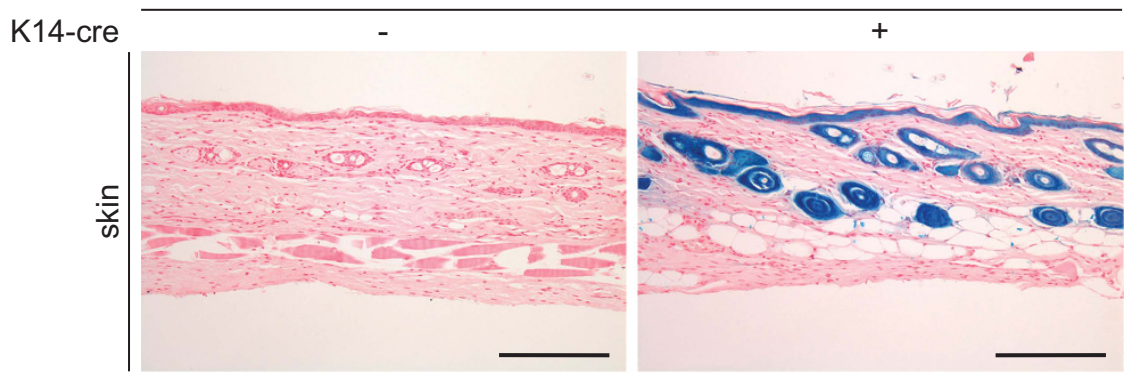

b

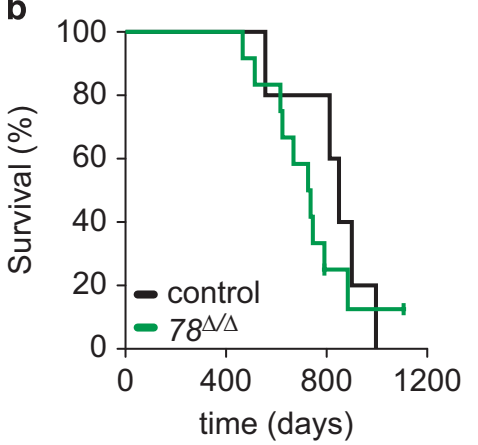

c

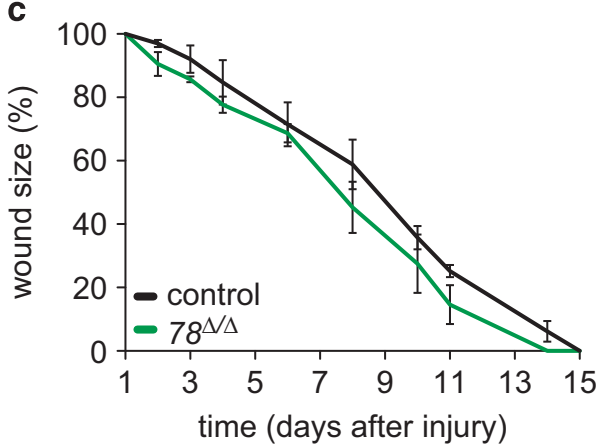

Figure 1. Keratin-14-Cre expression leads to specific deletion of genes in epidermis. (a) Microscopic pictures of normal skin of mice with indicated genotypes, stained with X-Gal. (b) Mice were followed to old age for survival analysis (control $n=5 ; 78^{\Delta / \Delta} n=12$ ). Differences are not statistically significant, log-rank, Mantel-Cox test. (c) A full-thickness biopsy wound was induced on the dorsal midline of mice ( $n=3$ per genotype). The height and width of the wound were measured and the wound area is described as the percentage relative to the wound area on day 1 after injury. 
a

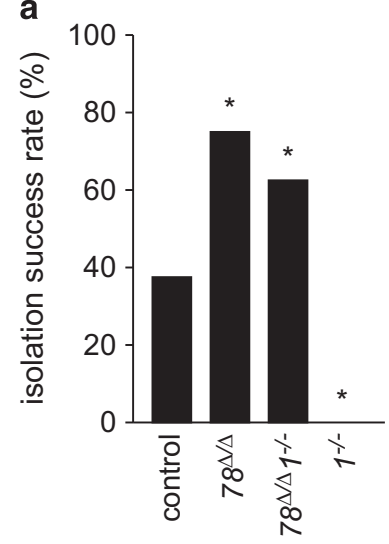

b

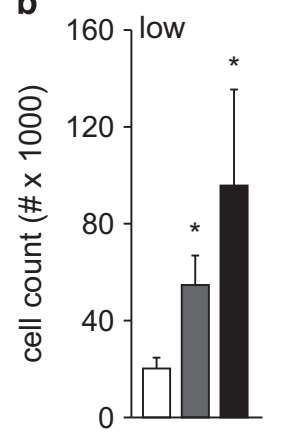

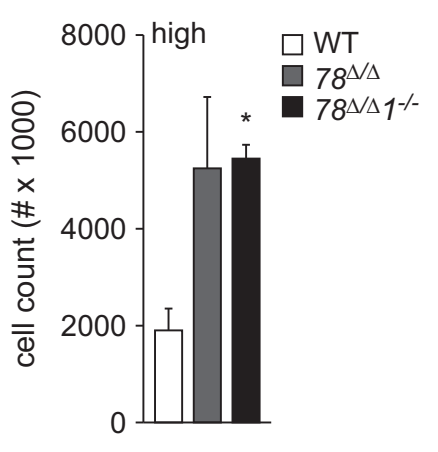

Figure 2. Isolation and culture of E2f7/E2f8 mutant keratinocytes. (a) Isolation success rate of primary mouse keratinocyte cultures (control, $78^{\Delta / \Delta}$ and $78^{\Delta / \Delta} 1^{-/-} n=8 ; 1^{-/-} n=2$ ). (b) Quantification of cell growth under low and high confluence. Cells were cultured for 8 days and counted ( $n=3$ per genotype). (a and b) $* P<0.05$ vs control.

$\mathrm{\gamma H} 2 \mathrm{Ax}$ levels in keratinocytes of all three genotypes (Figure 3a). The mean intensity for $\mathrm{YH} 2 \mathrm{Ax}$ staining between the three genotypes did not differ significantly, indicating that deletion of atypical E2Fs with or without E2F1 in murine keratinocytes had no major effect on DNA damage. Interestingly, $E 2 f 7^{\Delta / \Delta} E 2 f 8^{\Delta / \Delta} E 2 f 1^{-1-}$ keratinocytes exposed to DNA damage agents displayed a larger cell-to-cell variability of $\mathrm{\gamma H} 2 \mathrm{Ax}$ phosphorylation, where some cells displayed exceptional high levels and other cells showed very low levels (Figure 3a, Supplementary figure 2). This observation suggests that a subpopulation of $E 2 f 7^{\Delta / \Delta} E 2 f 8^{\Delta / \Delta} E 2 f 1^{-/-}$keratinocytes might have more DNA damage, which is in line with previous studies suggesting that E2F1 promotes DNA repair ${ }^{24,25}$ or that E2F1 is required for inducing apoptosis in cells exhibiting high levels of DNA damage. ${ }^{1}$ Interestingly, the appearance of $E 2 f^{\Delta / \Delta} E 2 f 8^{\Delta / \Delta} E 2 f 1^{-1-}$ keratinocytes with reduced DNA damage might suggest that E2F1 deficiency could also promote DNA repair in a certain subpopulation, however the mechanism is unclear.

A critical response to DNA damage is the induction of a cell cycle arrest through blocking DNA replication. Strikingly, analysis of $\mathrm{BrdU}$ incorporation revealed that neither $E 2 f 7^{\Delta / \Delta} E 2 f 8^{\Delta / \Delta}$ nor $E 2 f^{\Delta / \Delta} E 2 f 8^{\Delta / \Delta} E 2 f 1^{-1-}$ keratinocytes showed a reduction in DNA synthesis after etoposide treatment, whereas control cells showed a profound reduction in BrdU incorporation in response to etoposide (Figure $3 \mathrm{~b}$ ). These findings suggest that E2F7/8 are essential for the induction of an S-phase arrest in response to DNA damage.

We then investigated whether double- and triple-knockout keratinocytes could enter mitosis under DNA damaging conditions by evaluating phospho-Ser10-histone $\mathrm{H} 3(\mathrm{pH} 3)$ immunofluorescence staining. Notably, etoposide treatment reduced the number of pH3-positive control cells markedly, while $E 2 f 7^{\Delta / \Delta} E 2 f 8^{\Delta / \Delta}$ and $E 2 f 7^{\Delta / \Delta} E 2 f 8^{\Delta / \Delta} E 2 f 1^{-/-}$keratinocytes showed only partly reduced numbers of $\mathrm{pH} 3$-positive cells (Figure $3 \mathrm{c}$ ). Close inspection revealed that $\mathrm{pH} 3$-positive double- and triple-knockout cells in presence of etoposide exclusively showed a dotted pattern, indicating that these cells are in late G2-phase. No pan-nuclear $\mathrm{pH} 3$ staining or mitotic figures were seen in etoposide-treated $E 2 f 7^{\Delta / \Delta} E 2 f 8^{\Delta / \Delta}$ and $E 2 f 7^{\Delta / \Delta} E 2 f 8^{\Delta / \Delta} E 2 f 1^{-/-}$keratinocytes (Figure $3 c$ ). However, we detect mitotic figures in $E 2 f 7^{\Delta / \Delta} E 2 f 8^{\Delta / \Delta} E 2 f 1^{-1-}$ keratinocytes when we reduced the dose of etoposide to $5 \mu \mathrm{m}$, and in $E 2 f 7^{\Delta / \Delta} E 2 f 8^{\Delta / \Delta}$ and $E 2 f 7^{\Delta / \Delta} E 2 f 8^{\Delta / \Delta} E 2 f 1^{-/-}$keratinocytes when the concentration of etoposide was further reduced to $1 \mu \mathrm{M}$, while the control keratinocytes still show no $(5 \mu \mathrm{M})$, or highly reduced $(1 \mu \mathrm{m})$ mitotic staining (Figure $3 \mathrm{~d}$ ).

Next, we performed gene expression analysis to further evaluate the DNA damage response in keratinocytes. Western blot analysis showed strongly induced protein levels of P53 and its transcriptional target P21 Cip1 after etoposide treatment, in a comparable manner between control, $E 2 f 7^{\Delta / \Delta} E 2 f 8^{\Delta / \Delta}$ and $E 2 f 7^{\Delta / \Delta}$ $E 2 f 8^{\Delta / \Delta} E 2 f 1^{-1-}$ keratinocytes (Figure 3e), suggesting that the p53p21 axis in response to DNA damage is intact in these cells. Interestingly, etoposide treatment reduced Cyclin B1 protein in control, but not in $E 2 f 7^{\Delta / \Delta} E 2 f 8^{\Delta / \Delta}$ and $E 2 f 7^{\Delta / \Delta} E 2 f 8^{\Delta / \Delta} E 2 f 1^{-/-}$ keratinocytes (Figure 3e). This accumulation of Cyclin B1 in etoposide-treated double- and triple-knockout keratinocytes occurred independently of transcriptional regulation (Figure 3f), and is consistent with the $\mathrm{pH} 3$ data suggesting an accumulation of mutant keratinocytes in late G2-phase under DNA damaging conditions.

As E2F7 and E2F8 repress many genes relevant for entry and progression of DNA replication, we investigated the expression of E2F target genes in untreated and etoposide treated keratinocytes. The protein levels of the E2F target $\mathrm{CDC} 6$, an essential factor for DNA replication initiation, were markedly induced by loss of E2f7/8. Remarkably, additional E2f1 deletion, which is known to trans-activate $C d c 6$, did not rescue this induction. Etoposide treatment reduced the protein levels of CDC6 in control as well as double knockout and triple knockout keratinocytes (Figure 3e). However, protein levels of CDC6 in etoposide-treated $E 2 f 7^{\Delta / \Delta} E 2 f 8^{\Delta / \Delta}$ and $E 2 f 7^{\Delta / \Delta} E 2 f 8^{\Delta / \Delta} E 2 f 1^{-1-}$ keratinocytes were still similar to untreated control cells, consistent with a failure of double- and triple-knockout keratinocytes to block DNA synthesis during DNA damage. Transcript levels of $M c m 2$, another E2F target gene involved in DNA replication, showed a similar induction by loss of E2F7 and E2F8 as Cdc6 under both untreated and DNA damaging conditions (Figure $3 \mathrm{~g}$ ). Together, these data indicate that E2F7 and E2F8 are required to arrest primary keratinocytes in S-phase during DNA damage.

Loss of E2f1 inhibits apoptosis in $E 2 f 7^{\Delta / \Delta} E 2 f 8^{\Delta / \Delta}$ keratinocytes during in vitro and in vivo stress

Given that $E 2 f 7^{\Delta / \Delta} E 2 f 8^{\Delta / \Delta} E 2 f 1^{-/-}$keratinocytes reached higher cell numbers under low-confluence conditions than $E 2 f 7^{\Delta / \Delta} E 2 f 8^{\Delta / \Delta}$ keratinocytes (Figure 2b), we investigated whether E2F1 promotes apoptosis in $E 2 f 7^{\Delta / \Delta} E 2 f 8^{\Delta / \Delta}$ keratinocytes upon stress, such as exposure to different DNA damaging agents. qPCR and western blot analysis revealed that E2f1 RNA and protein levels were increased in keratinocytes lacking E2F7/8 (Supplementary Figure 1). We induced DNA damage in primary keratinocytes with either etoposide or camptothecin, and measured numbers of Annexin- $\mathrm{V}^{+}$cells by FACS analysis (Figures $4 \mathrm{a}$ and b). Etoposide and camptothecin caused a mild increase in apoptosis in control keratinocytes. The apoptotic response was enhanced in $E 2 f 7^{\Delta / \Delta}$ 
$E 2 f 8^{\Delta / \Delta}$ keratinocytes, in particular after camptothecin treatment. In contrast, the number of apoptotic cells was lower in $E 2 f 7^{\Delta / \Delta}$ $E 2 f 8^{\Delta / \Delta} E 2 f 1^{-/-}$keratinocytes compared with $E 2 f 7^{\Delta / \Delta} E 2 f 8^{\Delta / \Delta}$ keratinocytes, suggesting that E2F1 induces apoptosis in stressed keratinocytes lacking atypical E2Fs. To complement these findings by in vivo studies, we stressed the skin of control, $E 2 f 7^{\Delta / \Delta} E 2 f 8^{\Delta / \Delta}$ and $E 2 f 7^{\Delta / \Delta} E 2 f 8^{\Delta / \Delta} E 2 f 1^{-1-}$ mice with a single application of 7,12dimethylbenz[a]anthracene (DMBA), which leads to the formation of DNA adducts. Skin samples were harvested after $24 \mathrm{~h}$ to measure the numbers of apoptotic (TUNEL-positive) cells per $\mathrm{mm}$ of epidermis. Notably, $E 2 f 7^{\Delta / \Delta} E 2 f 8^{\Delta / \Delta}$ mice showed higher numbers of apoptotic cells compared with control littermates.
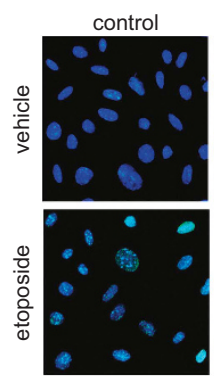

b

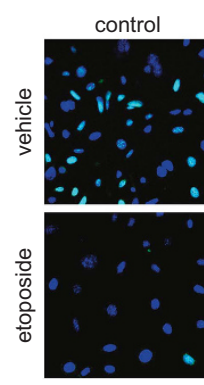

c

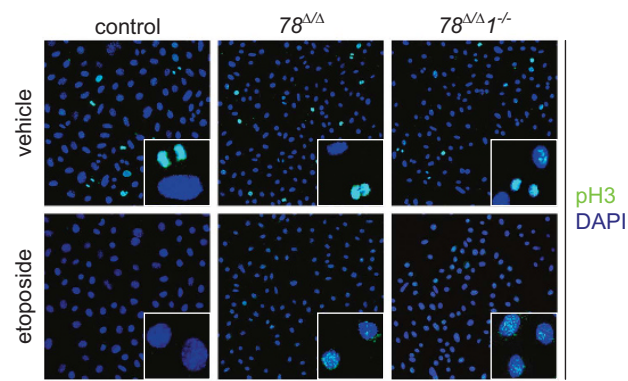

d

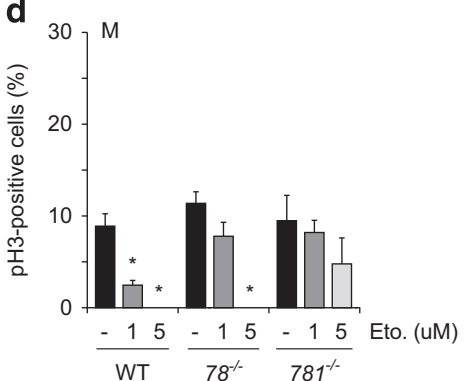

e

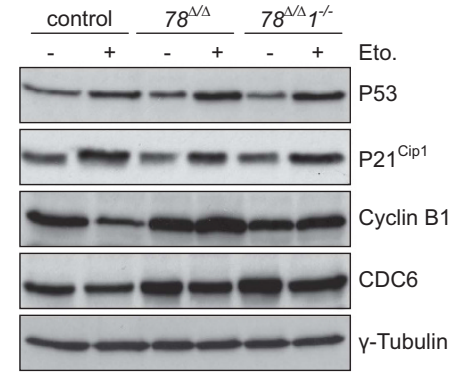

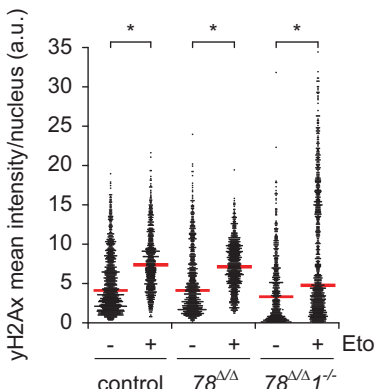
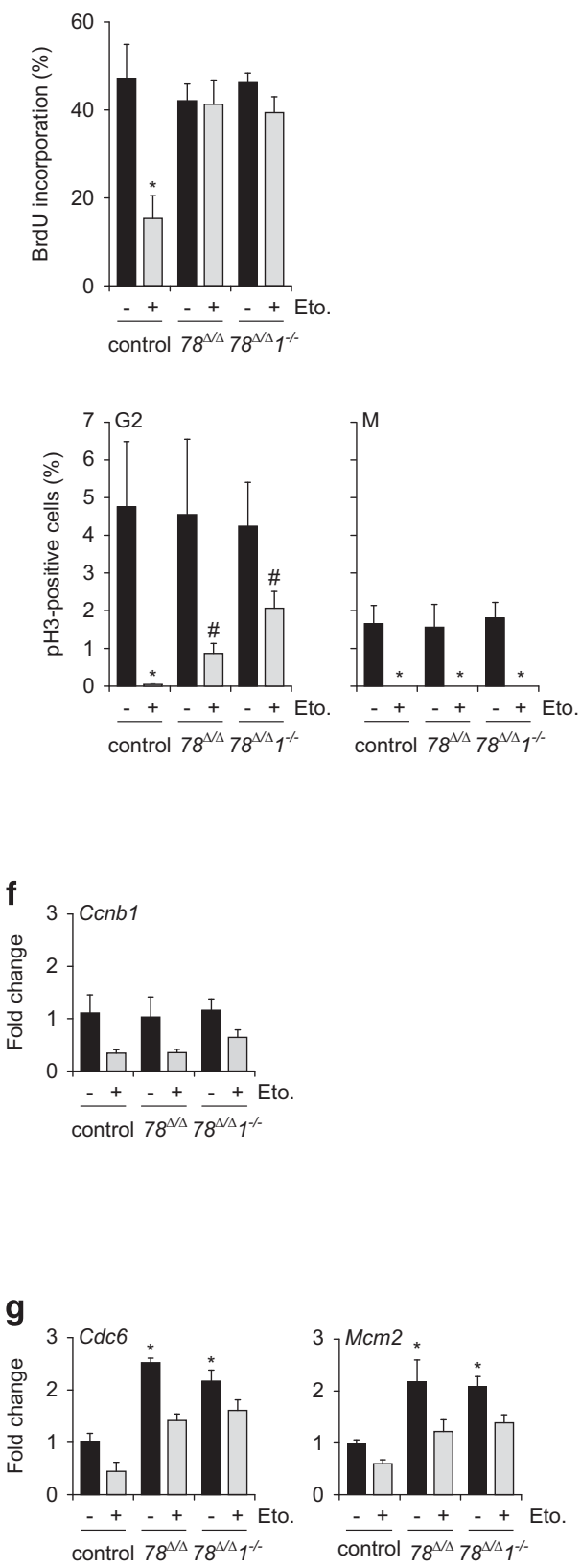
Importantly, in $E 2 f 7^{\Delta / \Delta} E 2 f 8^{\Delta / \Delta} E 2 f 1^{-/-}$mice this increase of apoptotic cells was reduced (Figure $4 c, P=0.06$ ). Collectively, we show that E2F1 mediates an enhanced apoptotic response to DNA damage in $E 2 f 7^{\Delta / \Delta} E 2 f 8^{\Delta / \Delta}$ keratinocytes.

Synergistic functions of E2F7 and E2F8 are critical for tumor suppression in the skin

Next, we determined whether atypical E2Fs contribute to longterm stress responses in vivo by performing a two-stage skin carcinogenesis study using DMBA and 12-O-tetradecanoyl-phorbol-13-acetate (TPA). Adult mice were exposed to a single dose of DMBA (tumor initiation), followed by TPA treatments twice a week (tumor promotion) for 15 weeks (Figure 5a). Strikingly, the combined deletion of $E 2 f 7 / 8$ caused a significant increase in the number of tumors per mouse over the course of TPA treatment (Figure 5b). Moreover, tumors in $E 2 f 7^{\Delta / \Delta} E 2 f 8^{\Delta / \Delta}$ mice grew significantly faster than control tumors (Figures $5 \mathrm{c}$ and d). We confirmed that K14-cre-mediated deletion occurred in the keratinocytes of skin tumors (Supplementary Figure 3). A boardcertified veterinary pathologist analyzed histology sections of tumors to evaluate malignant progression, and these were categorized into papilloma, carcinoma in situ, or squamous cell carcinoma (SCC) 1-3, where SCC-3 represents the most advanced stage (Figures $5 \mathrm{e}$ and $\mathrm{f}$ ). During 15 weeks of TPA treatment, none of the control tumors reached the SCC-2 or SCC-3 stages (invasion into dermis and subcutaneous muscle, respectively), whereas almost $20 \%$ of the $E 2 f 7^{\Delta / \Delta} E 2 f 8^{\Delta / \Delta}$ tumors did (Figure 5e). The tumor-suppressing effects of E2F7 and E2F8 are redundant, because mice with single conventional deletions of E2f7 or E2f8 did not show enhanced tumor formation or malignant progression compared with their control littermates (Supplementary Figure 4). In some in vivo mouse models, Cre activity can cause DNA damage and genetic instability. ${ }^{26,27}$ Therefore, we confirmed that Cre expression on its own did not increase tumor formation and progression. K14-Cre mice displayed no increase in tumor growth compared with wild-type littermates (Supplementary Figure 4). These findings demonstrate that E2F7 and E2F8 function as tumor suppressors in the skin when keratinocytes are exposed to oncogenic stress.

Loss of E2F1 accelerates tumorigenesis in E2F7/8-deficient skin tumors

As E2F1 is required to induce apoptosis in $E 2 f 7^{\Delta / \Delta} E 2 f 8^{\Delta / \Delta}$ keratinocytes under DNA damaging conditions (Figure 4), we investigated whether E2F1 contributes to the enhanced tumorigenesis observed in E2f7/8-deficient skin. Surprisingly, E2f $7^{\Delta / \Delta}$ $E 2 f 8^{\Delta / \Delta} \mathrm{E} \mathrm{f1} \mathrm{1}^{-/-}$mice developed significantly more and larger tumors than control and $E 2 f 7^{\Delta / \Delta} E 2 f 8^{\Delta / \Delta}$ littermates during twostage carcinogenesis (Figures $5 \mathrm{a}-\mathrm{c}$ ). In addition, tumors grew faster, and reached SSC-2 and SSC-3 stages more often (Figures $5 \mathrm{~d}$ and e). Moreover, we found metastatic nodules in adjacent lymph nodes of $E 2 f 7^{\Delta / \Delta} E 2 f 8^{\Delta / \Delta} E 2 f 1^{-1-}$ mice (3 out of 18), which were not observed in mice of the other genotypes (Figure $5 \mathrm{~g}$ ). Collectively, these results demonstrate that deletion of E2f1 further aggravates tumor progression in mice lacking E2F7 and E2F8. Importantly, deletion of E2f1 alone did not have a discernible effect in DMBA/ TPA-induced skin tumor formation compared with control mice (Supplementary Figure 5).

Atypical E2Fs and their target genes are upregulated in human squamous cell carcinomas

Since atypical E2Fs function as transcriptional repressors, we determined whether increased expression of atypical E2F target genes was observed in human squamous cell carcinomas. We analyzed a public microarray data set to compare expression of atypical E2F target genes in human cutaneous SCC and normal skin (GSE7553). We initially focused on all genes that showed E2F7 binding in proximal promoter regions by ChIP-sequencing in HeLa cells, an epithelial cancer cell line. ${ }^{4}$ From the 737 genes we previously identified as E2F7 targets, microarray expression data were available for 676 transcripts. We found that $~ 50 \%$ of these genes showed significantly altered expression in human SCC, most were upregulated, consistent with the loss of repressor function of atypical E2Fs (Figure 6a, Supplementary Table S4 up vs 84 down). As a consequence, normal skin and SCC samples could be distinguished by unsupervised hierarchical clustering based on the expression data of these 676 E2F7 target genes. Most of the 255 upregulated E2F7 genes in human SCC are well-known E2F target genes. Eighty percent of these E2F7 bound and upregulated genes contain at least one consensus E2F motif in their proximal promoters (Supplementary Figure 6). Gene ontology showed that DNA metabolism, DNA replication, DNA repair and related terms were highly overrepresented among the E2F7 target genes overexpressed in human SCC (Figure 6b, Supplementary Table S5).

Next, we determined the expression levels of the activator E2Fs and atypical E2Fs in human SCC samples (Figure $6 \mathrm{c}$ ). Of the activator arm of the E2F family, only E2F3 was significantly increased in human SCC. Remarkably, both atypical E2Fs were upregulated as well in human SCC, despite increased expression of many of their E2F target genes. As E2F7/8 promoters contain E2F-binding sites, ${ }^{9}$ their expression can be induced by activator E2Fs, presumably to counterbalance the E2F activity in proliferating cells.

Deregulated E2F7 target gene expression in SCC, despite high E2F7 and E2F8 transcript levels, raised the question if target genes were even further upregulated upon deletion of E2F7 and E2F8. To this end, we selected a panel of some of the most highly upregulated E2F target genes in human SCC samples (RRM2, CHEK1 and UHRF1; Figure $6 \mathrm{C}$ ), and evaluated the transcript levels of these targets in mouse SCC- 1 samples by qPCR. All these E2F target genes were consistently increased in $E 2 f 7^{\Delta / \Delta} E 2 f 8^{\Delta / \Delta}$ SCC-1 tumors compared with control tumors (Figure $6 \mathrm{~d}$ ). Importantly, triple-knockout SCCs showed a similar increase in the expression of E2F target genes, showing that additional deletion of E2f1 did not rescue the increased expression of these E2F targets in mouse

Figure 3. E2F7 and E2F8 inhibit DNA replication in response to DNA damage. (a) Representative immunofluorescence pictures and quantification of $\gamma \mathrm{H} 2 \mathrm{Ax}$ staining after $8 \mathrm{~h}$ etoposide treatment $(10 \mu \mathrm{m})$ in keratinocytes. Each plot represents $500-1000$ individual cells per independent keratinocyte line $(n=3)$. (b) DNA synthesis shown by BrdU incorporation after $8 \mathrm{~h}$ etoposide treatment $(10 \mu \mathrm{m})$ in keratinocytes. Averages per line were determined by analyzing 500-1000 cells ( $n=3$ per genotype). (c) Mitotic index of keratinocytes in response to $8 \mathrm{~h}$ of etoposide treatment $(10 \mu \mathrm{m})$, shown by $\mathrm{pH} 3$ staining. A dotted staining was indicative for late $\mathrm{G} 2$-phase, and pan-nuclear staining indicates mitotic (M) cells. Averages per line were determined by analyzing 500-1000 cells ( $n=3$ per genotype). (d) Mitotic index of keratinocytes in response to $8 \mathrm{~h}$ of etoposide treatment ( 1 or $5 \mu \mathrm{m}$, as indicated), shown by pan-nuclear pH3 staining. (e) Immunoblots showing expression of indicated proteins in whole cell lysates from keratinocytes of indicated genotypes after $8 \mathrm{~h}$ etoposide treatment (10 $\mu \mathrm{m})$. (f) qPCR analysis of Cyclin B1 transcripts in keratinocytes with indicated genotypes after $8 \mathrm{~h}$ etoposide treatment $(10 \mu \mathrm{M})$. Data are of 3-5 replicates, derived from three different lines per genotype. (g) Transcript levels of indicated E2F target genes in keratinocytes after $8 \mathrm{~h}$ etoposide treatment (10 $\mu \mathrm{M})$. Data are of $3-5$ replicates, derived from three different keratinocyte lines. (a-f) ${ }^{*} P<0.05$ vs control+vehicle; ${ }^{\#} P<0.05$ vs control+etoposide. 
a
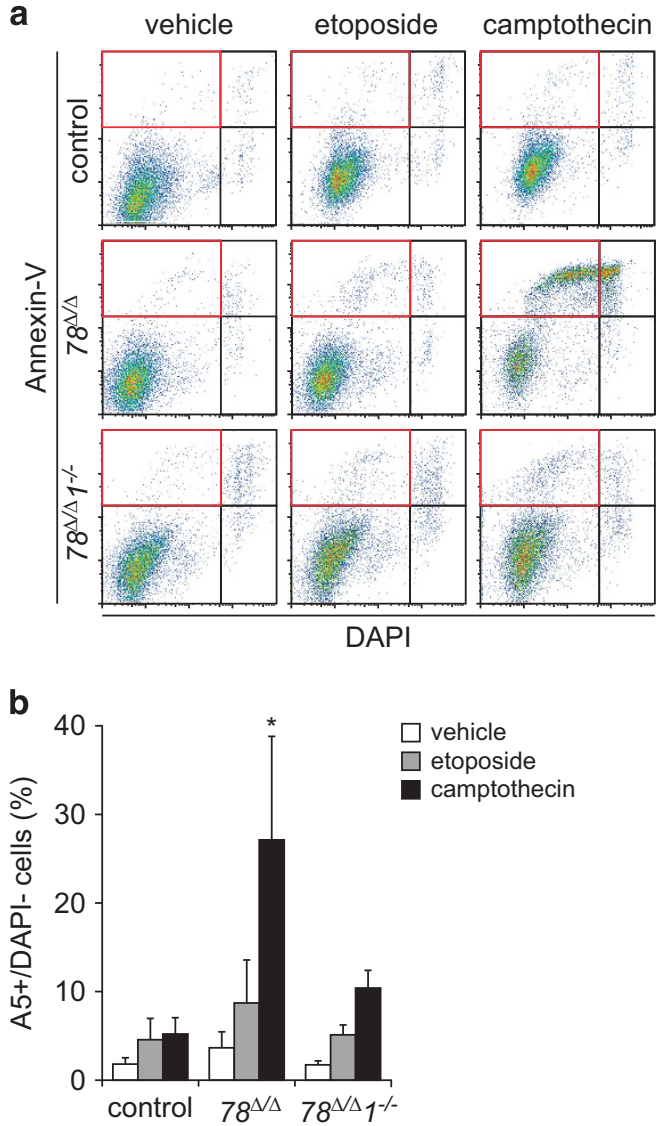

c
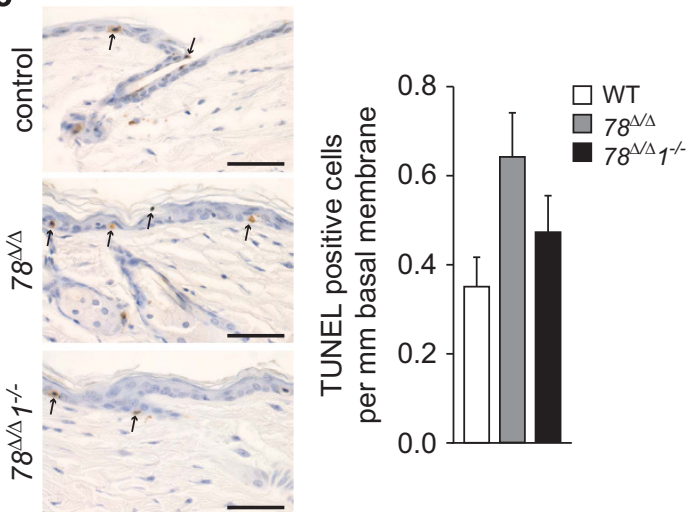

Figure 4. E2F1 induces apoptosis in keratinocytes during prolonged DNA damage. (a) FACS analysis of apoptosis in keratinocytes after $24 \mathrm{~h}$ of treatment with etoposide $(50 \mu \mathrm{m})$ or camptothecin $(20 \mu \mathrm{m})$. Live cells were labeled with Annexin-V (A5) and DAPI. Cells staining positive for $\mathrm{A} 5$ and negative for DAPI (A5+/DAPI ${ }^{-}$, red boxes) are apoptotic. (b) Quantification of the $\mathrm{A}^{+} / \mathrm{DAPI}^{-}$populations in the FACS plots ( $n=3$ per genotype). ${ }^{*} P<0.05$ vs control. (c) Representative TUNEL staining and quantification of mouse epidermis, $24 \mathrm{~h}$ after a single application of DMBA. Data are presented as number of TUNEL-positive cells per mm epidermis (control $n=10 ; 78^{\Delta / \Delta}$ and $78^{\Delta / \Delta} 1^{-1-} n=12$ ).

SCC deficient for atypical E2Fs (Figure 6d). These observations suggest that E2F1 tumor suppressor activities in $E 2 f 7^{\Delta / \Delta} E 2 f 8^{\Delta / \Delta}$ SCCs are most likely not related to regulating E2F target genes involved in DNA metabolism, replication or repair.

In conclusion, atypical E2F target genes are induced during human cutaneous SCC, and we show that loss of E2F7 and E2F8 further deregulates expression of these genes in mouse cutaneous
SCC, which associates with enhanced tumorigenesis. These findings suggest that atypical E2Fs act as tumor suppressors through transcriptional repression of deregulated E2F target genes that drive DNA metabolism and replication in skin cancer.

\section{DISCUSSION}

Misregulation of E2F-dependent transcription is a frequent event in many different cancers and is thought to be a critical driver of uncontrolled proliferation of cancer cells. However, the functions and contributions of individual E2F family members in various types of cancer are complex and poorly understood. ${ }^{1}$ This is especially true for the most recently discovered family members, E2F7 and E2F8. Previous studies in cancer cell lines and human tumor specimens have yielded conflicting results. Some studies suggested that atypical E2Fs might function as oncogenes, while other studies indicate that they might acts as tumor suppressors, suggesting that the roles of E2F7 and E2F8 depend on the tissue type and the kind of mutation. Also, all of these studies were performed in cell lines, or by analysis of patient samples. ${ }^{19,28-31}$ Here we provide the first in vivo evidence that synergistic function of E2F7 and E2F8 are required for tumor suppression in the skin.

We used the two-stage skin carcinogenesis model to demonstrate that atypical E2Fs function as tumor suppressors. This carcinogenesis model induces oncogenic stress with activation of Ras oncogenes and accumulation of other DNA mutations, and subsequent transformation of cells. ${ }^{32}$ One defense mechanism against this type of stress is the activation of a transient or permanent cell cycle arrest via DNA damage response. ${ }^{33}$ We show that E2F7 and E2F8 inhibit DNA replication under DNA damaging conditions in keratinocytes, suggesting that atypical E2Fs suppress tumorigenesis by inducing a cell cycle arrest. Two recent papers show that E2F7 transcription is induced by P53 during DNA damage. ${ }^{7,8}$ We found that keratinocytes deleted for E2f7 and E2f8 show a normal induction of P53 and its downstream target gene P21 in response to DNA damage, suggesting that E2F7 could indeed act as an important mediator of the P53-dependent cell cycle arrest. However, it should be noted that the regulation of atypical E2Fs in response to DNA damage might be more complex. E2F8 is not a confirmed P53 target, ${ }^{7,8}$ but its induction in response to DNA damage has previously been reported in cell lines. ${ }^{6}$

A striking observation in our study was that deletion of E2f1 aggravated tumorigenesis in E2f7/8-deficient skin. Similar observations have been made in other mouse models, where deletion of E2f1 enhances tumorigenesis in a Myc-transgenic mouse model, and in mice with skin-specific deletion of $\mathrm{Rb}^{34,35}$ Nevertheless, we and others previously demonstrated that E2F1 counterbalances the functions of E2F7/8 during various physiological processes such as embryonic development and liver polyploidization, which was also reflected by opposite regulation of an overlapping set of target genes. ${ }^{5,18,20}$ This is clearly different in the current skin cancer model, as additional deletion of E2f1 did not alter the expression of multiple E2F target genes in the present study. This could be related to the fact that other activator E2Fs might compensate for the loss of E2F1 as it has been previously observed. $^{36}$

E2F1 has at least two non-redundant functions that may affect skin tumorigenesis. First, E2F1 can localize to sites of DNA damage. ${ }^{24}$ This localization involves phosphorylation of Ser29 and interestingly, phosphorylation-dead $E 2 f 1^{S 29 A}$ knock-in mice are prone to develop UV-induced skin tumors. ${ }^{37}$ Deletion of E2F1 in the DMBA-TPA model had no discernible effect on tumor progression, suggesting that E2F1 tumor suppression function might be dependent on the type or dose of DNA damage. When E2F1 was deleted in combination with atypical E2Fs, the average amount of $\mathrm{\gamma H} 2 \mathrm{Ax}$ phosphorylation in response to DNA damage did not differ compared with control cells, suggesting that E2F1 
DMBA TPA

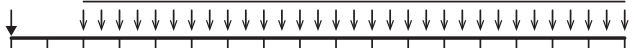

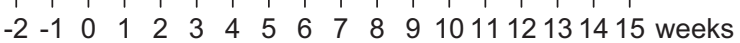

b
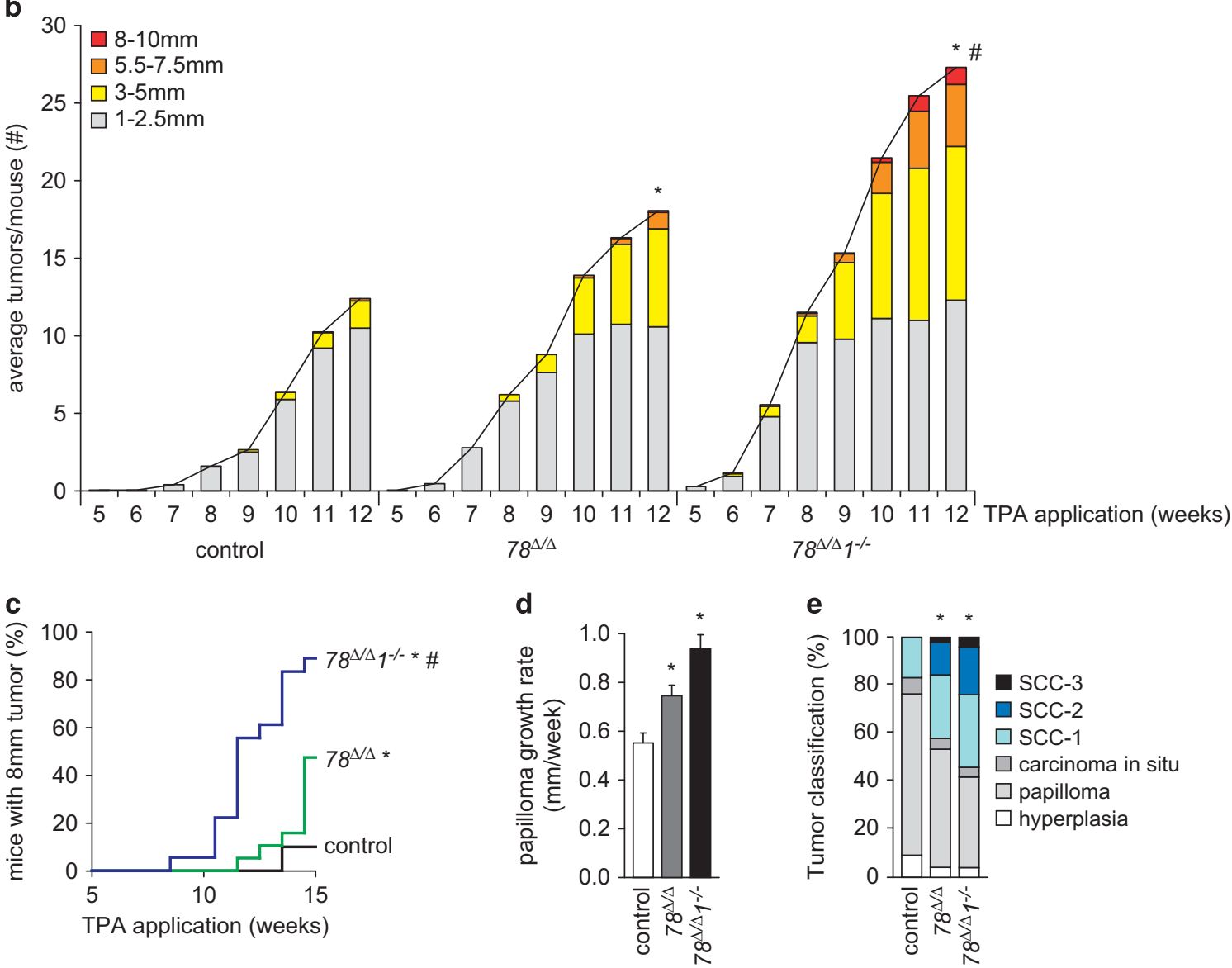

f

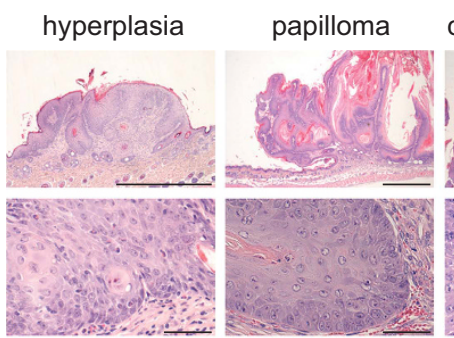

carcinoma in situ

SCC-1
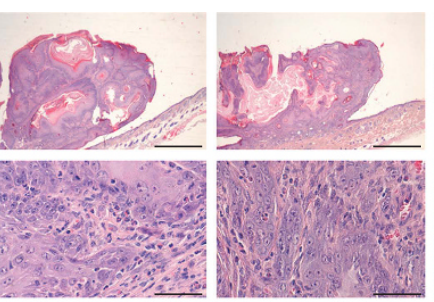

SCC-2

SCC-3
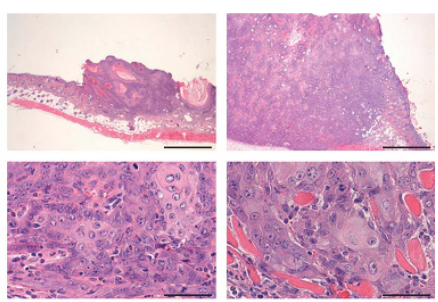

g

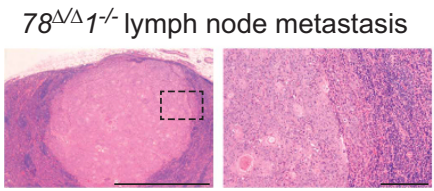

Figure 5. Atypical E2Fs inhibit tumor growth and progression in DMBA/TPA-induced carcinogenesis. (a) Two weeks after a single dermal application of DMBA (initiation), bi-weekly applications of TPA (promotion) were performed for a period of 15 weeks, as indicated by arrows. (b) Average number of tumors per mouse, classified by tumor diameter, during the first 12 weeks of TPA treatment (control $n=20$; $78^{\Delta / \Delta} n=19$; $\left.78^{\Delta / \Delta} 1^{-1-} n=18\right) .{ }^{*} P<0.05$ compared with control, ${ }^{\#} P<0.05$ vs $78^{\Delta / \Delta}$, one-way ANOVA on repeated measurements with Bonferroni correction for multiple testing. (c) Cumulative incidence of large tumors (diameter $>8 \mathrm{~mm}$; control $n=20 ; 78^{\Delta / \Delta} n=19 ; 78^{\Delta / \Delta} 1^{-/-} n=18$ ). ${ }^{*} P<0.001$ vs control, ${ }^{\#} P<0.001$ vs $78^{\Delta / \Delta}$, log-rank, Mantel-Cox test. (d) Average papilloma growth rates (control $n=99 ; 78^{\Delta / \Delta} n=85 ; 78^{\Delta / \Delta} 1^{-/-} n=71$ ). ${ }^{*} P<0.05$ vs control. (e) Quantification of malignant progression by histological classification of skin tumors. The following categories were distinguished: hyperplasia; papilloma; carcinoma in situ; SCC grade 1; grade 2; grade 3. ${ }^{*} P<0.001$ vs control, chi-square test. (f) Representative photos of tumor stages quantified in e. Scale bars indicate $1 \mathrm{~mm}$ in low-magnification pictures and $50 \mu \mathrm{m}$ in high-magnification pictures. (g) Representative photos of lymph-node metastasis observed in $78^{\Delta / \Delta} 1^{-1-}$ mice. Scale bar indicates $1 \mathrm{~mm}$ in low magnification and $200 \mu \mathrm{m}$ in high-magnification picture. 

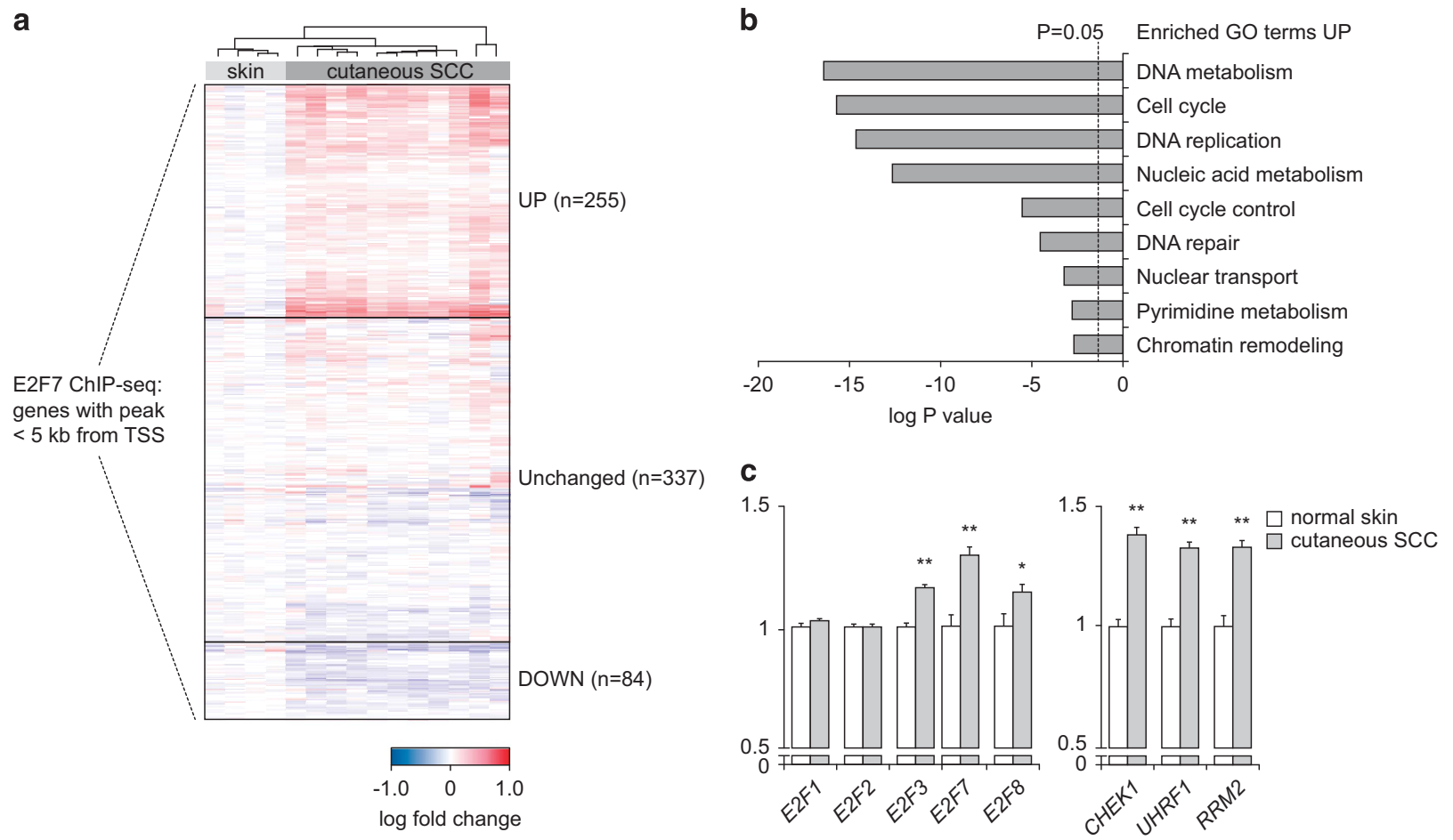

d

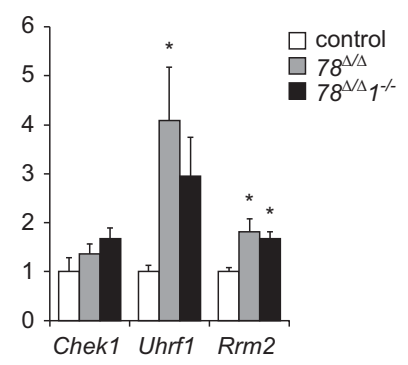

Figure 6. E2F7-target genes are highly expressed in human SCC and are further increased by the deletion of E2f7 and E2f8. (a) Heatmap showing expression of E2F7 target genes in human cutaneous SCC and normal skin. (b) PANTHER gene ontology (GO) analysis of the 255 upregulated E2F7 target genes as shown in heatmap. Benjamini-adjusted log $P$-values were calculated using DAVID. ${ }^{49}$ (c) Expression of E2F family members and E2F target genes in human cutaneous SCC, determined by the Riker microarray data ${ }^{48}$ (normal skin $n=4 ; \mathrm{SCC} n=11$ ). (d) Evaluation of transcript levels of E2F target genes in mouse SCC-1 samples (control $n=6 ; 78^{\Delta / \Delta} n=7 ; 78^{\Delta / \Delta} 1^{-/-} n=8$ ).

might not be required for DNA repair. However, closer inspection at single cell level revealed that there was a subpopulation of triple-knockout cells that expressed extremely high levels of phosphorylated $\mathrm{\gamma H} 2 \mathrm{Ax}$ in response to DNA damage, indicating that inactivation of E2F1 resulted in more DNA damage in a subset of cells that might be more prone to transformation. Alternatively, cells with unrepaired DNA might be less cancer-prone, because they could die due to catastrophic events during mitosis. Interestingly, we observed that a subpopulation of E2f7/8/1deficient keratinocytes displayed reduced DNA damage, indicating that E2f1 deficiency might also promote DNA repair. If this enhanced DNA repair events are more error-prone it could increase the chance of oncogenic transformation and could thereby represent another mechanism for the enhanced tumorigenesis phenotype in E2f7/8/1-deficient keratinocytes.

However, another potential mechanism how E2F1 could function as tumor suppressor in the skin is its ability to induce apoptosis. $^{38,39}$ DNA damage leads to multiple post-translational modifications of E2F1, resulting in stabilization and increased binding and transactivation of pro-apoptotic target genes, including P73, Caspase-3 and Apaf1. 25,39,40 Suppression of apoptosis is a hallmark of cancer and can drive progression of many cancer types, including squamous cell carcinomas. ${ }^{41,42}$
We show that inactivation of E2f1 in E2f7/8 deficient keratinocytes suppresses apoptosis in vitro and in vivo, which is line with previous in vitro studies. ${ }^{6,19}$ These findings suggest that E2F1 functions as a tumor suppressor by inducing apoptosis in E2f7/8deficient keratinocytes under stress conditions.

Similar to E2F1, E2F7 has also been shown to localize and bind to regions of DNA damage. ${ }^{22}$ In this study, inactivation of E2F7 in $\mathrm{U} 2 \mathrm{OS}$ cells resulted in increased phosphorylation of $\mathrm{Y}-\mathrm{H} 2 \mathrm{AX}$ after recovery of camptothecin-induced DNA damage. These findings indicate that E2F7 might be required for proper DNA repair and could represent a potential tumor-suppressor function of atypical E2Fs. However in our studies, we have not detected any significant differences in phosphorylation of $\mathrm{\gamma}-\mathrm{H} 2 \mathrm{AX}$ between wild-type and $\mathrm{E} 2 \mathrm{~F} / 8$-deficient murine keratinocyte in response to etoposide. The reason for this discrepancy is unclear, but might be related to the different experimental settings, such as choice of DNA damaging drug, species and cell type.

Our studies demonstrate that combined deletion of E2f7 and E2f8 in keratinocytes resulted in upregulation of E2F target genes under DNA-damaging conditions and in mouse skin tumors, which is consistent with the transcriptional repressor function of atypical E2Fs, ${ }^{40,19}$ Many of these atypical E2Fs target genes are involved in the initiation and progression of DNA replication. ${ }^{4}$ 
Importantly, these atypical E2F7/8 target genes were also upregulated in human squamous cell carcinomas, indicating that deregulation of E2F7/8 target genes might contribute to skin tumorigenesis in mice and humans. Evaluation of the COSMIC and TCGA databases revealed that genetic alterations of E2F7 and E2F8 are very infrequent, and the chance that both atypical E2Fs are mutated in the same tumor is extremely small. Therefore, forcing tumor cells to express high levels of E2F7 and/or E2F8 could be a promising strategy to inhibit E2F activity in tumor cells. We show that deletion of atypical E2Fs in skin tumors leads to further deregulation of E2F target genes accompanied with acceleration of tumorigenesis indicating that atypical E2Fs can counterbalance deregulated E2F activity to suppress tumorigenesis. For that reason, further enhancement of atypical E2Fs activity to downregulate E2F activity in tumor cells could represent a successful strategy to mitigate tumorigenesis, for example through blocking degradation of atypical E2Fs. Further investigations are required to examine how and when E2Fs are degraded, but studies from our group and others provide evidence that atypical E2Fs are degraded by the APC/C ${ }^{\mathrm{Cdh} 1}$ complex. ${ }^{43,44}$ These findings might open new avenues for therapeutic approaches to inhibit abundant E2F activity during tumorigenesis. Future studies are required to investigate how the activity of activator E2Fs and atypical E2Fs can be optimally manipulated to inhibit tumor growth for different cancer types.

\section{MATERIALS AND METHODS}

Animals

The use of laboratory animals was approved by the Animals Ethics Committee at Utrecht University and performed according to the institutional and national guidelines. Conventional and conditional E2f7 and E2f8-knockout mice were generated as described. ${ }^{18} \mathrm{~K} 14-\mathrm{Cre}$ and $\mathrm{R} 26 \mathrm{R}-$ $L_{\text {Lac }} Z^{\text {LOXPLLXP }}$ mice were purchased from Jackson Laboratory (Bar Harbor, $M E$, USA). Conventional E2f1 knockout mice were provided by $M$ Greenberg (Duke University Medical Center, USA). All mice were bred in FVB genetic background for at least five generations. Genotypic analysis of mice was performed on DNA from ear-clips by PCR. Primer sequences are shown in Supplementary Table S1. Animals were allocated to experimental groups based on their genotype and the analysis of the mice was performed in randomized and blinded manner.

\section{$\beta$-galactosidase staining}

Staining on skin and tumor tissues was performed as described previously. ${ }^{20}$

\section{Wound healing}

Dorsal skin of 6-week-old mice was shaved and $6 \mathrm{~mm}$ diameter circular full-thickness biopsy wounds were induced at the dorsal midline, removing both epidermis and dermis. The height and width of the wounds was measured at indicated time points after injury to assess the healing rates of the wounds. The wound area is described as the percentage relative to the wound area on day 1 after injury.

\section{Primary keratinocyte isolation}

Primary mouse keratinocytes were isolated from E17- to E19-day-old embryos following previously described protocol ${ }^{45}$ and cultured in defined keratinocyte CnT-medium (CELLnTEC, Bern, Switzerland, Advanced Cell Systems AG, CnT-07). The success rate was defined as the percentage of successful isolation and subsequent culturing primary murine keratinocyte cell lines in relation to the total number of isolation attempts per genotype group. When primary keratinocytes were established and cultured for more than three passages from the skin of a mouse embryo, this was counted as a successful isolation.

\section{Cell count}

Keratinocytes were plated under low $\left(7000 \mathrm{cells} / \mathrm{cm}^{2}\right)$ or high $(177.000$ cells $/ \mathrm{cm}^{2}$ ) confluency conditions. Cells growing under low confluency were counted 8 days after plating. Cells growing under high confluency were passaged once at 4 days, and counted after 8 days.

\section{Immunofluorescence microscopy}

Keratinocytes were cultured on glass coverslips, treated with etoposide $(10 \mu \mathrm{m})$ for $8 \mathrm{~h}$ and fixed in 4\% PFA for $10 \mathrm{~min}$ at room temperature. For 5bromo-2'-deoxyuridine (BrdU) detection, cells were treated with BrdU (Sigma, St Louis, MO, USA, B5002) $6 \mathrm{~h}$ before fixation. Cells were incubated with $2 \mathrm{M} \mathrm{HCl}$ for $20 \mathrm{~min}$, followed by addition of $0.1 \mathrm{M}$ sodium borate $\left(\mathrm{Na}_{2} \mathrm{~B}_{4} \mathrm{O}_{7}\right), \mathrm{pH} 8.5$ for $2 \mathrm{~min}$. Cells were washed with PBS and permeabilized with $0.2 \%$ triton/PBS for $5 \mathrm{~min}$. Immunofluorescence staining was done by anti-BrdU-FITC for $2 \mathrm{~h}$. Coverslips were mounted on slides using Fluoroshield mounting medium containing DAPI (Sigma, F6057).

Cells were fixed with $4 \%$ PFA/0.1\% triton/PBS for $10 \mathrm{~min}$ at room temperature for immunofluorescence staining for $\mathrm{\gamma}-\mathrm{H} 2 \mathrm{Ax}$ and $\mathrm{pH}$. Cells were blocked with $4 \%$ BSA/TBS for $30 \mathrm{~min}$, and incubated for $2 \mathrm{~h}$ with primary antibodies dissolved in 2\% BSA/TBS. Cells were washed and incubated with a secondary antibody conjugated with Alexa-Fluor 488 for $1 \mathrm{~h}$. DAPI was used as nuclear counterstaining. Images were taken using a Leica TCS SPE-II confocal microscope and analyzed using Fiji software. ${ }^{46}$ Used antibodies are in Supplementary Table S2.

\section{Western blot analysis}

Protein isolation and western blot analysis were performed as previously described. ${ }^{4}$ Used antibodies are in Supplementary Table S2. Uncropped versions of the western blots are shown in Supplementary Figure 7.

qPCR

RNA isolation, CDNA synthesis and qPCR were done as described. ${ }^{20}$ Gene expression was calculated using a $\Delta \Delta \mathrm{Ct}$ method adapted for multiple reference genes correction, ${ }^{47}$ correcting for b-actin and Gapdh (mouse tumors) or $18 \mathrm{~S}$ ribosomal RNA and Gapdh (keratinocytes). Primer sequences are included in Supplementary Table S3.

\section{Flow cytometry}

Keratinocytes were treated $24 \mathrm{~h}$ with etoposide $(50 \mu \mathrm{m})$ or camptothecin $(20 \mu \mathrm{m}$; Sigma C9911), and trypsinized. Annexin V-staining was performed according to the manufacturer's protocol (Invitrogen, Carlsbad, CA, USA, A13202). DAPI ( $1 \mathrm{ng} / \mathrm{ml})$ was added to the samples to distinguish between apoptotic and necrotic cells. After filtration of the cell suspensions on $40 \mu \mathrm{M}$ cell strainers (Falcon, Amsterdam, The Netherlands), analysis was performed with a BD FACS Canto II and quantifications were done using FlowJo software (TreeStar Inc., Ashland, OR, USA).

\section{Immunohistochemistry}

Apoptosis in microscopic mouse skin sections was detected using ApoTag Plus peroxidase In Situ Apoptosis Kit (TUNEL) (Chemicon, Southampton, UK, S701) according to manufacturer's protocol. All slides were counterstained with hematoxylin. TUNEL-positive cells per $\mathrm{mm}$ epidermis was determined manually.

\section{Two-stage carcinogenesis protocol}

The two-stage carcinogenesis protocol was performed as described previously. ${ }^{32}$ For short-term experiments, $25 \mathrm{nmol}$ DMBA/200 $\mu$ l acetone was topically applied to skin of 7-9-week-old mice, which were killed $24 \mathrm{~h}$ after application. Treated and untreated skin sections were fixed in $4 \%$ PFA for histological analysis.

\section{Comparative gene expression analysis}

The Gene Expression Omnibus was used to find previously published human cutaneous SCC data sets, and found one Affymetrix HGU113plus2 data set $\left(\mathrm{GSE} 7553^{48}\right)$. The raw data (.CEL) files from the squamous cell carcinoma $(n=11)$ and normal skin samples $(n=4)$ were analyzed using Flexarray 1.6.1 software (University of Quebec, Montreal, Canada). Raw Affymetrix data were normalized using RMA, and tested for significant differences between normal skin and SCC using Empirical Bayes estimation (Wilson \& Wright, New Haven, CT, USA). Using a previously published ChIPsequencing analysis, ${ }^{4}$ we filtered only those genes from the microarray data that have significant E2F7 binding within their promoter regions ( $<5 \mathrm{~kb}$ from transcription start site). Unsupervised hierarchical clustering 
based on expression of all E2F7 target genes was performed using the Euclidian distance method. E2F binding motif analysis was performed as described. ${ }^{4}$ Heatmaps reflecting normalized expression data were generated using Gene-E (https://www.broadinstitute.org/cancer/soft ware/GENE-E/). Gene ontology analysis of E2F7 target genes according to expression changes in human SCC was performed using PANTHER Biological Pathways tool in DAVID. ${ }^{49}$

\section{Statistics}

Data are presented as mean \pm s.e.m. unless indicated otherwise. Differences between groups were compared using one-way analysis of variance followed by Tukey's post hoc correction. When multiple groups were not normally distributed, Kruskal-Wallis tests with Dunn's post hoc correction were performed. Analysis was performed using SigmaPlot (Systat Software, San Jose, CA, USA).

\section{CONFLICT OF INTEREST}

The authors declare no conflict of interest.

\section{ACKNOWLEDGEMENTS}

This work was financially supported by a Dutch Cancer Society grant (KWF: UU2013-5777) to BW and AdB, and the Netherlands Organization of Scientific Research (NWO-ALW:843.11.002). We like to thank M Greenberg (Duke University Medical Center, USA) for kindly providing the E2f1 conventional knockout mice, and R Caldelari (University of Berne, Switzerland) for technical assistance and advice with the keratinocyte isolations. We are also thankful for the technical support by Elsbeth van Liere and Ronald Molenbeek (Utrecht University, The Netherlands).

\section{REFERENCES}

1 Chen H-Z, Tsai S-Y, Leone G. Emerging roles of E2Fs in cancer: an exit from cell cycle control. Nat Rev Cancer 2009; 9: 785-797.

2 Chellappan SP, Hiebert S, Mudryj M, Horowitz JM, Nevins JR. The E2F transcription factor is a cellular target for the RB protein. Cell 1991; 65: 1053-1061.

3 Johnson DG, Degregori J. Putting the oncogenic and tumor suppressive activities of E2F into Context. Curr Mol Med 2006; 6: 731-738.

4 Westendorp B, Mokry M, Groot Koerkamp MJA, Holstege FCP, Cuppen E, de Bruin A. E2F7 represses a network of oscillating cell cycle genes to control S-phase progression. Nucleic Acids Res 2012; 40: 3511-3523.

5 Chen H-Z, Ouseph MM, Li J, Pécot T, Chokshi V, Kent L et al. Canonical and atypical E2Fs regulate the mammalian endocycle. Nat Cell Biol 2012; 14: 1192-1202.

6 Zalmas LP, Zhao X, Graham AL, Fisher R, Reilly C, Coutts AS et al. DNA-damage response control of E2F7 and E2F8. EMBO Rep 2008; 9: 252-259.

7 Carvajal LA, Hamard P-J, Tonnessen C, Manfredi JJ. E2F7, a novel target, is up-regulated by p53 and mediates DNA damage-dependent transcriptional repression. Genes Dev 2012; 26: 1533-1545.

8 Aksoy O, Chicas A, Zeng T, Zhao Z, McCurrach M, Wang X et al. The atypical E2F family member E2F7 couples the p53 and RB pathways during cellular senescence. Genes Dev 2012; 26: 1546-1557.

9 de Bruin A, Maiti B, Jakoi L, Timmers C, Buerki R, Leone G. Identification and characterization of E2F7, a novel mammalian E2F family member capable of blocking cellular proliferation. J Biol Chem 2003; 278: 42041-42049.

10 Di Stefano L, Jensen MR, Helin K. E2F7, a novel E2F featuring DP-independent repression of a subset of E2F-regulated genes. EMBO $J$ 2003; 22: 6289-6298.

11 Logan N, Delavaine L, Graham A, Reilly C, Wilson J, Brummelkamp TR et al. E2F-7: a distinctive E2F family member with an unusual organization of DNA-binding domains.Oncogene 2004; 23: 5138-5150.

12 Logan N, Graham A, Zhao X, Fisher R, Maiti B, Leone G et al. E2F-8: an E2F family member with a similar organization of DNA-binding domains to E2F-7. Oncogene 2005; 24: 5000-5004.

13 Christensen J, Cloos P, Toftegaard U, Klinkenberg D, Bracken AP, Trinh E et al. Characterization of E2F8, a novel E2F-like cell-cycle regulated repressor of E2F-activated transcription. Nucleic Acids Res 2005; 33: 5458-5470.

14 Maiti B, Li J, de Bruin A, Gordon F, Timmers C, Opavsky R et al. Cloning and characterization of mouse E2F8, a novel mammalian E2F family member capable of blocking cellular proliferation. J Biol Chem 2005; 280: 18211-18220.
15 Hazar-Rethinam M, Cameron SR, Dahler AL, Endo-Munoz LB, Smith L, Rickwood D et al. Loss of E2F7 expression is an early event in squamous differentiation and causes derepression of the key differentiation activator Sp1. J Invest Dermatol 2011; 131: 1077-1084.

16 Hazar-Rethinam M, de Long LM, Gannon OM, Topkas E, Boros S, Vargas AC et al. A novel E2F/sphingosine kinase 1 axis regulates anthracycline response in squamous cell carcinoma. Clin Cancer Res 2015; 21: 417-427.

17 Ouseph MM, Li J, Chen H-Z, Pécot T, Wenzel P, Thompson JC et al. Atypical E2F repressors and activators coordinate placental development. Dev Cell 2012; 22: 849-862.

18 Li J, Ran C, Li E, Gordon F, Comstock G, Siddiqui H et al. Synergistic function of E2F7 and E2F8 is essential for cell survival and embryonic development. Dev Cell 2008; 14: 62-75

19 Endo-Munoz L, Dahler A, Teakle N, Rickwood D, Hazar-Rethinam M, Abdul-Jabbar I et al. E2F7 can regulate proliferation, differentiation, and apoptotic responses in human keratinocytes: implications for cutaneous squamous cell carcinoma formation. Cancer Res 2009; 69: 1800-1808.

20 Pandit SK, Westendorp B, Nantasanti S, van Liere E, Tooten PCJ, Cornelissen PWA et al. E2F8 is essential for polyploidization in mammalian cells. Nat Cell Biol 2012; 14: 1181-1191.

21 D'Souza SJA, Vespa A, Murkherjee S, Maher A, Pajak A, Dagnino L. E2F-1 is essential for normal epidermal wound repair. J Biol Chem 2002; 277: 10626-10632.

22 Zalmas L-P, Coutts AS, Helleday T, La Thangue NB. E2F-7 couples DNA damagedependent transcription with the DNA repair process. Cell Cycle 2013; 12: 3037-3051.

23 Hande KR. Etoposide: four decades of development of a topoisomerase II inhibitor. Eur J Cancer 1998; 34: 1514-1521.

24 Biswas AK, Johnson DG. Transcriptional and nontranscriptional functions of E2F1 in response to DNA damage. Cancer Res 2012; 72: 13-17.

25 Carnevale J, Palander O, Seifried LA, Dick FA. DNA damage signals through differentially modified E2F1 molecules to induce apoptosis. Mol Cell Biol 2012; 32: 900-912.

26 Schmidt-Supprian M, Rajewsky K. Vagaries of conditional gene targeting. Nat Immunol 2007; 8: 665-668.

27 Silver DP, Livingston DM. Self-excising retroviral vectors encoding the Cre recombinase overcome Cre-mediated cellular toxicity. Molecular Cell 2001; 8: 233-243.

28 Salvatori B, losue I, Mangiavacchi A, Loddo G, Padula F, Chiaretti S et al. The microRNA-26a target E2F7 sustains cell proliferation and inhibits monocytic differentiation of acute myeloid leukemia cells. Cell Death Dis 2012; 3: e413.

29 Reimer D, Sadr S, Wiedemair A, Stadlmann S, Concin N, Hofstetter G et al. Clinical relevance of E2F family members in ovarian cancer--an evaluation in a training set of 77 patients. Clin Cancer Res 2007; 13: 144-151.

30 Deng Q, Wang Q, Zong W-Y, Zheng D-L, Wen Y-X, Wang K-S et al. E2F8 contributes to human hepatocellular carcinoma via regulating cell proliferation. Cancer Res 2010; 70: 782-791.

31 Park S-A, Platt J, Lee JW, López-Giráldez F, Herbst RS, Koo JS. E2F8 as a Novel Therapeutic Target for Lung Cancer. J Natl Cancer Inst 2015; 107: djv151-1, 1-16.

32 Abel EL, Angel JM, Kiguchi K, DiGiovanni J. Multi-stage chemical carcinogenesis in mouse skin: fundamentals and applications. Nat Protoc 2009; 4: 1350-1362.

33 Di Micco R, Fumagalli M, Cicalese A, Piccinin S, Gasparini P, Luise C et al. Oncogene-induced senescence is a DNA damage response triggered by DNA hyper-replication. Nature 2006; 444: 638-642.

34 Rounbehler RJ, Rogers PM, Conti CJ, Johnson DG. Inactivation of E2f1 enhances tumorigenesis in a Myc transgenic model. Cancer Res 2002; 62: 3276-3281.

35 Costa C, Santos M, Martínez-Fernández M, Dueñas M, Lorz C, García-Escudero R et al. E2F1 loss induces spontaneous tumour development in Rb-deficient epidermis. Oncogene 2013; 32: 2937-2951.

36 Tsai S-Y, Opavsky R, Sharma N, Wu L, Naidu S, Nolan E et al. Mouse development with a single E2F activator. Nature 2008; 454: 1137-1141.

37 Biswas AK, Mitchell DL, Johnson DG. E2F1 responds to ultraviolet radiation by directly stimulating DNA repair and suppressing carcinogenesis. Cancer Res 2014; 74: 3369-3377.

38 DeGregori J, Leone G, Miron A, Jakoi L, Nevins JR. Distinct roles for E2F proteins in cell growth control and apoptosis. Proc Natl Acad Sci USA 1997; 94: 7245-7250.

39 Polager S, Ginsberg D. p53 and E2f: partners in life and death. Nat Rev Cancer 2009; 9: 738-748.

40 Pediconi N, lanari A, Costanzo A, Belloni L, Gallo R, Cimino L et al. Differential regulation of E2F1 apoptotic target genes in response to DNA damage. Nat Cell Biol 2003; 5: 552-558. 
41 Hanahan D, Weinberg RA. Hallmarks of cancer: the next generation. Cell 2011; 144: 646-674.

42 Kim C, Pasparakis M. Epidermal p65/NF-kB signalling is essential for skin carcinogenesis. EMBO Mol Med 2014; 6: 970-983.

43 Cohen M, Vecsler M, Liberzon A, Noach M, Zlotorynski E, Tzur A. Unbiased transcriptome signature of in vivo cell proliferation reveals pro- and antiproliferative gene networks. Cell Cycle 2013; 12: 2992-3000.

44 Boekhout M, Yuan R, Wondergem AP, Segeren HA, van Liere EA, Awol N et al. Feedback regulation between atypical E2Fs and APC/CCdh1 coordinates cell cycle progression. EMBO Rep 2016; 17: 414-427.

45 Caldelari R, Müller EJ. Short- and long-term cultivation of embryonic and neonatal murine keratinocytes. Methods Mol Biol 2010; 633: 125-138.

46 Schindelin J, Arganda-Carreras I, Frise E, Kaynig V, Longair M, Pietzsch T et al. Fiji: an open-source platform for biological-image analysis. Nat Methods 2012; 9: 676-682.

47 Vandesompele J, De Preter K, Pattyn F, Poppe B, Van Roy N, De Paepe A et al. Accurate normalization of real-time quantitative RT-PCR data by geometric averaging of multiple internal control genes. Genome Biol 2002; 3: RESEARCH0034, 1-12.
48 Riker Al, Enkemann SA, Fodstad O, Liu S, Ren S, Morris C et al. The gene expression profiles of primary and metastatic melanoma yields a transition point of tumor progression and metastasis. BMC Med Genomics 2008; 1: 13.

49 Huang DW, Sherman BT, Lempicki RA. Systematic and integrative analysis of large gene lists using DAVID bioinformatics resources. Nat Protoc 2009; 4: 44-57.

(c) (i) $\Theta$ This work is licensed under a Creative Commons AttributionNonCommercial-NoDerivs 4.0 International License. The images or other third party material in this article are included in the article's Creative Commons license, unless indicated otherwise in the credit line; if the material is not included under the Creative Commons license, users will need to obtain permission from the license holder to reproduce the material. To view a copy of this license, visit http:// creativecommons.org/licenses/by-nc-nd/4.0/

(c) The Author(s) 2017

Supplementary Information accompanies this paper on the Oncogene website (http://www.nature.com/onc) 